\title{
ERCP'nin nadir bir komplikasyonu: Subkapsüler hematom
}

\author{
A rare complication of ERCP: Subcapsular hematoma
}

\section{Özlem GÜL UTKU, Bilal ERGÜL, Oktay AYDIN, Dilek OĞUZ}

Kırlkkale Üniversitesi Tip Fakültesi, Gastroenteroloji Bilim Dalı, Kinkkale

Endoskopik retrograd kolanjiyopankreatografi pankreatikobiliyer hastalıklarin tedavisinde kullanılan girişimsel bir endoskopik yöntemdir. Pankreatit, kanama ve perforasyon en sık görülen komplikasyonlandır. Subkapsüler hematom, endoskopik retrograd kolanjiyopankreatografinin literatürde birką adet bildirilmiş olan nadir bir komplikasyonudur. Bu bildiride, kolelitiazis nedeniyle endoskopik retrograd kolanjiyopankreatografi yapılan yaşlı bir hastada işlem sonrasında subkapsüler hematom gelişen bir olguyu sunuyoruz.

Anahtar kelimeler: Endoskopik retrograd kolanjiyopankreatografi, komplikasyon, subkapsüler hematom
Endoscopic retrograd cholangiopancreatography is an interventional endoscopic method for the treatment of pancreaticobiliary diseases. Pancreatitis, bleeding and perforation are the most common complications. Subcapsular hematoma is a rare complication of endoscopic retrograd cholangiopancreatography that has been only a few reported in the literature. In this report, we present a case of subcapsular hematoma developing in an elderly patient after endoscopic retrograd cholangiopancreatography performed due to cholelithiasis.

Key words: Endoscopic retrograd cholangiopancreatography, complication, subcapsular hematoma

\section{GIIRİS}

Endoskopik retrograd kolanjiyopankreatografi (ERCP), pankreatikobilier hastalıkların teşhis ve tedavisinde 1968'den itibaren kullanılan önemli bir endoskopik yöntemdir. Tanısal kullanımı endoskopik ultrasonografi ve manyetik rezonans kolanjiyopankreatografi gibi daha az invaziv ve invaziv olmayan yöntemlerin gelişmesi ile yok denecek kadar azalmıştır. Terapötik alanda kullanımı ise giderek artmıştır. Güvenli sayllmakla beraber endoskopik işlemler arasında en yüksek komplikasyon oranlarına sahiptir. En sık gözlenen komplikasyonları pankreatit, hemoraji, perforasyon ve kolanjittir. ERCP sonrası semptomatik hastaların ayırıcı tanısında düşünülmesi gereken nadir komplikasyonlardan biri de subkapsüler hematomdur. Biz bu raporda, sağ üst kadranda ağrı ve ateş ile prezente olan ve post-ERCP subkapsüler hematom gelişen bir olguyu sunduk.

\section{OLGU SUNUMU}

Seksen üç yaşında erkek hasta sağ üst kadran ağrısı, üşüme, titreme ve sarllık şikâyeti ile acil servise başvurdu. Fizik muayenesinde $38^{\circ} \mathrm{C}$ ateş, sağ üst kadran hassasiyeti, cilt ve skleralarda sarllı mevcuttu. Laboratuvar değerlendirmesinde aspartat aminotransferaz (AST): $55 \mathrm{U} / \mathrm{L}$, alanin aminotransferaz
(ALT): $127 \mathrm{U} / \mathrm{L}$ gama glutamil transpeptidaz (GGT): $220 \mathrm{U} / \mathrm{L}$ alkalen fosfataz (ALP): 200 U/L, total bilirubin: 4,5 direk bilirubin: 3,2 ve beyaz küre 17.400 mm3/ul \%96 nötrofil hakimiyeti tespit edildi. Abdominal ultrasonografisinde intra-ekstrahepatik safra yollarında dilatasyon ve koledokta taş saptandı. Manyetik rezonans kolanjiyopankreatografide koledok geniş, sistik kanal birleşim yeri distalinde taş ile uyumlu görünüm izlendi (Resim 1). Yapılan ERCP'de koledoktan yaklaşık $1 \mathrm{~cm}$ büyüklüğünde taş çıkarıldı. Isşlemden yaklaşık 8 saat sonra sırta ve omuza yayılan şiddetli sağ üst kadran ağrısı oldu. Laboratuvar değerlerinde amilaz ve lipaz düzeyleri normal sınırlardaydı. Medikal tedaviye rağmen devam eden ağrısı mevcuttu, fizik muayenede tansiyon arteriyel 80/60 mm-Hg, nabız 104/dk ve batın muayenesinde rijidite ve defansı olması nedeni ile hastaya abdominal tomografi çekildi. Sağ lob subkapsüler alanda yaklaşı 10x8 $\mathrm{cm}$ boyutunda içerisinde santral pnömobili bulunan hematom, perisplenik interloop mesafede ve pelvik bölgede en derin yerinde $6 \mathrm{~cm}$ ölçülen serbest sıvı izlendi (Resim 2,3). Hastanın hemoglobin değerleri 14,6 gr/dl den 12,6 gr/dl'ye geriledi. Subkapsüler hematom ile birlikte serbest sıvı olması, nedeni ile hastaya cerrahi drenaj uygulandı ve yaklaşık $1.000 \mathrm{cc}$ hematom boşaltıldı. Takibinin yedinci gününde hasta şifa ile taburcu edildi. 


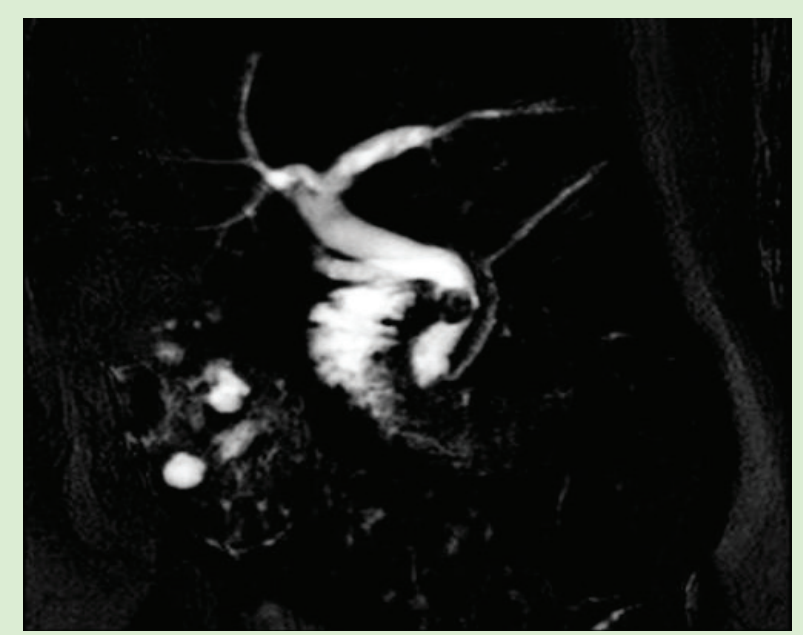

Resim 1. Koledok distalinde taş

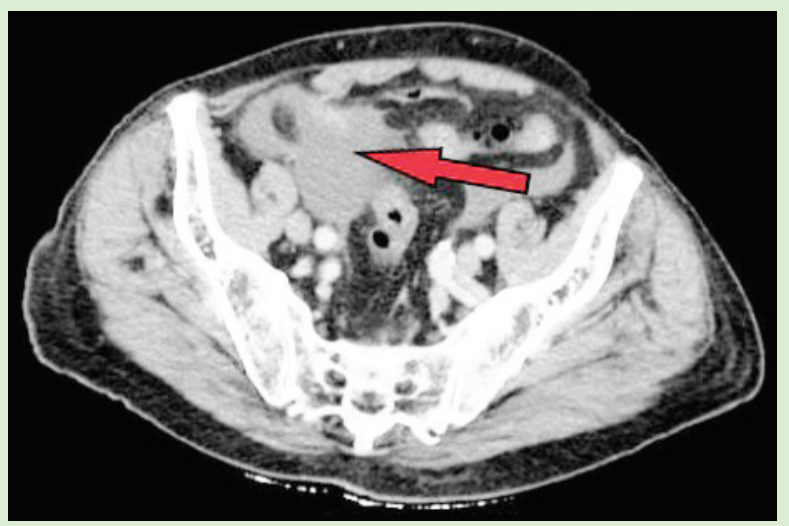

Resim 2. Sağ subkapsüler içerisinde santral pnömobili bulunan hematom

\section{TARTISSMA}

Endoskopik retrograd kolanjiyopankreatografi minimal invaziv bir yöntemdir. ERCP ilişkili ciddi komplikasyon oranı \%2.5-8, mortalite oranı ise \%0.5-1'dir. Papillotomi sonucu ortaya çıkan pankreatit, kolanjit, perforasyon ve kanamalar en sik bildirilen komplikasyonlardır (1).

Subkapsüler hematom, ERCP sonrası oluşan hayatı tehdit eden nadir bir komplikasyondur. Günümüzde literatürde birkaç vaka bildirilmiştir. Küçük parankimal damarların ve intrahepatik safra yollarının kılavuz telle laserasyonu ile ilişkili olabileceği hipotezi öne sürülmekle beraber oluşum mekanizması hala net değildir (2-4). Klinik olarak ERCP sonrası ani başlangıçlı ağrı, hipotansiyon ve taşikardi en sık görülen

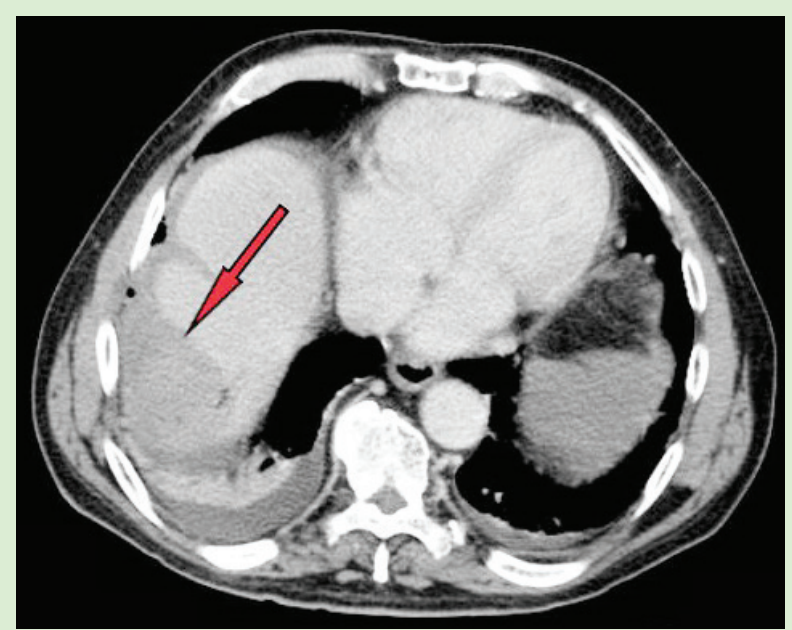

Resim 3. Pelvik bölgede serbest SIVI

bulgularıdır. Ağrı, Glisson kapsülünün gerilmesine bağlı oluşur. Anemi, ateş ve periton iritasyon bulguları diğer tanımlanmış semptomlarıdır. Genellikle hemoglobin düşüşü dışında laboratuvar testlerinde önemli bir işaret yoktur. Ultrasonografi ve tomografi gibi görüntüleme yöntemleri tanıda altın standarttır (4). Hastanın hemodinamisi ve klinik durumuna göre tedavi yöntemi seçilir. Sınırl, periferal hematomu olan stabil hastalarda antibiyotik tedavisi ile konservatif tedavi ve bu süreçte hemoglobin takibi önerilmektedir. Apse oluşumu ve ateş durumunda ultrasonografi veya tomografi eşliğinde perkütan drenaj, hemodinamik instabilite, aktif kanama ve kontrast ekstravazasyonu, periton iritasyon bulguları, serbest abdominal sıvı olması durumunda cerrahi girişim önerilmektedir (5). Diğer tedavi yöntemi, ilişkili damarların selektif ya da süperselektif embolizasyonudur. Hematomun ani spontan rüptürü ile gelişen hemoperitoneum, tanıda gecikilirse yüksek mortalite riski taşıyan ciddi bir durumdur ve acil cerrahi tedavi gerektirir. Literatürde tedavi olarak konservatif tedavi (\%43.5), perkütan embolizasyon (\%26), drenaj (\%17.4) ve cerrahi tedavi (\%13) uygulanmıştır (6). Bizim olgumuza hemodinamik instabilite ve intarabdominal serbest sıvı olması nedeni ile cerrahi tedavi uygulandi.

Subkapsüler hepatik hematomun erken tanısı ile hastalara uygun tedavi yöntemi seçilerek klinik stabilite sağlanabilirken, komplike olgularda tanıda gecikme olduğunda mortal seyredebilir. Bu nedenle, ERCP sonrası ani karın ağrısı, eşlik eden hipotansiyon, taşikardi ve/veya periton iritasyon bulguları olan olguların ayırıcı tanısında dikkate alınması gereken önemli bir komplikasyondur. 


\section{KAYNAKLAR}

1. Hart R, Classen M. Complications of diagnostic gastrointestinal endoscopy. Endoscopy 1990;22:229-33.

2. Abdel Aziz AM, Lehman GA. Pancreatitis after endoscopic retrograde cholangio-pancreatography. World J Gastroenterol 2007;13:2655-68.

3. Cotton PB, Garrow DA, Gallagher J, Romagnuolo J. Risk factors for complications after ERCP: a multivariate analysis of 11.497 procedures over 12 years. Gastrointestinal Endoscopy 2009;70:80-8.

4. Zappa MA, Aiolfi A, Antonini I, et al. Subcapsular hepatic haematoma of the right lobe following endoscopic retrograde cholangiopancreatography: Case report and literature review. World J Gastroenterol 2016;22:4411-5.
5. Fei BY, Li CH. Subcapsular hepatic haematoma after endoscopic retrograde cholangiopancreatography: an unusual case. World J Gastroenterol 2013;19:1502-4

6. Zizzo M, Lanaia A, Barbieri I, et al. Subcapsular hepatic hematoma after endoscopic retrograde kholangiopancreatography: A case report and review of literature. Medicine (Baltimore) 2015;94:e1041. 